\title{
A case of bone lesion in a patient with relapsed chronic lymphocytic leukemia and review of the literature
}

\author{
Francesca Bacchiarri ${ }^{1}$, Alessandro Gozzetti ${ }^{1}$, Nicola Mondanelli ${ }^{1}$, Stefano Lazzi ${ }^{1}$, and \\ Monica Bocchia ${ }^{1}$ \\ ${ }^{1}$ University of Siena
}

April 8, 2021

\begin{abstract}
Skeletal involvement in CLL is very rare. We present a case of ileum bone lesion during in a patient receiving 5 th line of therapy. Despite radiotherapy and salvage therapies, subsequent bone lesions led to a fatal outcome. Further studies on the mechanism by which bone disease develops are currently needed.
\end{abstract}

A case of bone lesion in a patient with relapsed chronic lymphocytic leukemia and review of the literature

Francesca Bacchiarri ${ }^{1}$, Alessandro Gozzetti ${ }^{1}$, Nicola Mondanelli $^{2}$, Stefano Lazzi ${ }^{3}$, Monica Bocchia ${ }^{1}$

${ }^{1}$ University of Siena, Department of Hematology, Siena, Italy

${ }^{2}$ University of Siena, Department of Orthopedic Surgery, Siena, Italy

${ }^{3}$ University of Siena, Anatomic Pathology department, Siena, Italy

Corresponding author: Francesca Bacchiarri, MD

Email: francesca.bacchiarri@hotmail.it

Address: University of Siena, Viale Bracci 16, 53100- Siena, Italy

Phone: +390577586798

Fax: +390577586185

Keywords: chronic lymphocytic leukemia, hypercalcemia, osteolysis

\section{ABSTRACT}

Skeletal involvement in CLL is very rare. We present a case of ileum bone lesion during in a patient receiving 5th line of therapy. Despite radiotherapy and salvage therapies, subsequent bone lesions led to a fatal outcome. Further studies on the mechanism by which bone disease develops are currently needed.

KEY CLINICAL MESSAGE

The mechanism by which bone lesions develop in CLL is unclear, further studies are needed in this regard, with the aim of developing more effective therapies. This case aims to review the literature, the modality of presentation and pathogenesis.

INTRODUCTION 
Chronic lymphocytic leukemia (CLL) is the most common leukemia in the Western world, with a predominance in the elderly and an increasing incidence with age. ${ }^{1}$ Characterized by heterogeneous clinical course, CLL has predominantly a B-cell origin, with a clonal expansion of mature CD5+ CD23+ B-lymphocytes that accumulate in the bone marrow and infiltrate lymphoid tissues such as the spleen and lymph nodes. ${ }^{2}$

Treatment has changed over the last 30 years from chemotherapy, to chemo-immunotherapy and lately to novel agents (i.e. BTK inhibitors and BCL-2 inhibitor). ${ }^{3-5}$

Rarely, patients can experience a skeletal progression, variously associated with hypercalcemia, as reported by some authors. Herein we present a case of skeletal progression in a patient with a 10-year history of CLL with del17p and unmutated IGHV, receiving venetoclax as $5^{\text {th }}$ line of therapy.

\section{CASE PRESENTATION}

The patient was diagnosed with CLL in 2009: he presented with a mild lymphocytosis, diffuse lymphadenopathies (laterocervical and axillary lymph nodes of maximum diameter $2 \mathrm{~cm}$ ), splenomegaly and left testicular swelling. Bone marrow aspiration was positive for CLL (CD5+ CD19+ CD23+ CD20+ CD38+); fluorescence in situ hybridization (FISH) analysis showed chromosome $17 \mathrm{p}$ delection (20\% of nucleated cells), and unmutated IGHV. The patient underwent left orchiectomy, that confirmed CLL diagnosis. After 4 cycles of chemotherapy with fludarabine and alemtuzumab, he obtained a partial remission of the disease. Patient underwent maintenance therapy with rituximab until October, 2012. In December 2012, due to a disease relapse with anemia, splenomegaly and lymphadenopathy, $2^{\text {nd }}$ line therapy with rituximab and bendamustine was started. After 4 cycles, patient was in stable disease, therefore a therapy with alemtuzumab and cyclophosphamide was administered from April to September 2013.

Patient remained asymptomatic until June 2014, when massive splenomegaly, anemia and lymphocytosis were again found. A therapy with BTK inhibitor (ibrutinib) was started. For an episode of autoimmune haemolytic anemia he required corticosteroids therapy. Patient obtained a partial remission and continued ibrutinib until March 2018, when a therapy with BCL-2 inhibitor (venetoclax) was started for massive lymph nodes enlargement. Patient had a complete remission until August, 2019 when he was admitted to the Emergency Unit for lower limbs pain complained for about 2 months. Radiographs and CT-scan demonstrated a left iliac bone pathological fracture due to a bone lesion that also affected the soft intrapelvic tissues, occupying and replacing the iliopsoas muscle (maximum diameter of the lesion $10 \mathrm{~cm}$ ), as shown in Figure 1. A core needle bone biopsy performed under radiographic guidance confirmed CLL diagnosis (Figure 2). Physical examination revealed no lymphadenopathy nor organomegaly. Laboratory findings showed no lymphocytosis with WBC $2.3 \times 10^{9} / \mathrm{L}$ (lymphocyte count 15\%), Hb $11.4 \mathrm{~g} / \mathrm{dL}$, platelets $137 \mathrm{x}$ $10^{9} / \mathrm{L}$. Serum total proteins were low $(5.6 \mathrm{~g} / \mathrm{dL})$, without monoclonal component. Uric acid $(4.3 \mathrm{mg} / \mathrm{dL})$ and serum alkaline phosphatase (125 U/L) were normal, with elevated calcium (14.6 mg/dL), $\beta 2$-microglobulin $(4.9 \mathrm{mg} / \mathrm{L})$ and serum lactate dehydrogenase $(250 \mathrm{U} / \mathrm{L})$. PTH analysis was not performed. Bone marrow aspiration showed CLL infiltrate.

The fracture was treated conservatively, and radiotherapy was administered at the dose of 30 Gy, but other lytic lesions of the contralateral acetabulum, $3^{\text {rd }}$ left rib and left clavicle leading to pathological fractures occurred. The patient was subsequently treated with 1 cycle of intravenous rituximab, continuing with venetoclax plus zoledronic acid as prophylaxis. Despite the radiotherapy and intensification of immunotherapy, patient developed multiple cranial lytic lesions, involving epidural and dural tissue and left occipitotemporal leptomeningeal infiltration, and he died 3 months later.

\section{DISCUSSION}

CLL is the commonest form of leukemia, presenting often with asymptomatic peripheral lymphocytosis. The clinical course can be very heterogenous with lymphadenopathy, increased incidence of infection, autoimmune phenomena (e.g., haemolytic anemia, thrombocytopenia), and B symptoms (fever, unintentional weight loss, night sweats, and severe fatigue). Active treatment is required with advanced disease stage, evidence of disease progression (e.g., cytopenias, lymphadenopathy of $10 \mathrm{~cm}$, and/or splenomegaly), and/or in the 
presence of constitutional B symptoms. In case of relapse, the presentation can be identical or characterized by transformation to high-grade lymphoma (Ricther's syndrome) ${ }^{6}$. Macroscopic skeletal involvement is extremely rare, being more frequent in other lymphoproliferative disease and some acute leukemias. Altered bone metabolism, resorption, and demineralization can lead to an increased risk of spine and pelvic fractures in untreated patients. ${ }^{7-9}$

Some cases in literature have already described the presence of lytic lesions in patients affected by CLL, and one of them was previously described by our group. ${ }^{10}$

In 11 on 22 cases of the literature, patients had the axial skeleton or proximal long bones involved ${ }^{10-21}$ and in rare cases fractures were localized to the skull or facial bones. ${ }^{17,22,23}$ Multiple fractures were reported in 8 cases. ${ }^{24-31}$

Like this one, other cases in the literature described pathological fracture due to CLL involving the spine and vertebral compression fractures. ${ }^{16,19,29,30}$ Of note, in 13 reports symptomatic osteolysis was the first presentation of a CLL. The cases reported in the literature are summarized in table 1. Interestingly, pathological fracture can be also the first presentation of a newly diagnosed CLL. Hypercalcemia is a frequent finding with osteolysis, and can be related to Richter's transformation, or co-occurring multiple myeloma. The pathogenesis is not well understood, and can be related to primary hyperparathyroidism, ${ }^{32}$ increased serum immunoreactive parathormone (iPTH), or osteoclast activating factor $(\mathrm{OAF}) .{ }^{33}$

In a recent study ${ }^{34}$ bone erosion was particularly evident in long bone shafts, progressively increased from Binet stage A to Binet stage C, and it was directly related to the number of RANKL + cells present in the circulating blood. Also, after denosumab administration to CLL cells in vitro the expression of RANK decreased and also cell proliferation, this could partially be explained by the interaction between CLL lymphocytes and stromal cells.

\section{CONCLUSIONS}

Our patient had a 10-year history of CLL, with several relapses, and eventually developed multiple osteolytic lesions associated with hypercalcemia. PTH analysis was not performed, however in an end-stage disease characterized by several skeletal lytic lesions hypercalcemia can be a common finding.

The pathogenesis of bone involvement in CLL is not completely understood, and it is associated with Richter disease in the majority of cases. Of note, in 13 cases patients developed bone metastases / presented symptomatic bone lesions as first presentation of a CLL.

Bone erosions in patient affected by CLL can be related to an increased expression of RANK or locally released osteoclast stimulating factors.

This overview suggests that bone lesion are not rare events in CLL and further investigation is required to clarify the underlying mechanism and to find suitable therapies for this group of patients, which often presents a high morbidity and mortality.

\section{AUTORSHIP}

FB wrote the manuscript, AG followed the patient, NM performed patient's bone biopsy, SL analyzed bone biopsy, MB designed the study. All authors have contributed to, read and approved the manuscript and this submission.

\section{ETHICS STATEMENT}

relatives of the deceased patient were informed and agreed to the publication.

\section{CONFLICT OF INTEREST}

The authors of this paper have no conflicts of interest, including specific financial interests, relationships, and/or affiliations relevant to the subject matter or materials included. 


\section{REFERENCES}

1. Baumann T, Delgado J, Santacruz R, et al. Chronic lymphocytic leukemia in the elderly: clinicobiological features, outcomes, and proposal of a prognostic model. Haematologica. 2014; 99(10):1599604

2. Chiorazzi N, Rai KR, Ferrarini M. Chronic lymphocytic leukemia. $N$ Engl J Med. 2005; 352(8):804-15.

3. Zinzani PL, Lauria F, Rondelli D, et al. Fludarabine in patients with advanced and/or resistant B-chronic lymphocytic leukemia. Eur J Haematol . 1993;51(2):93-97.

4. Laurenti L, Innocenti I, Autore F, et al. Bendamustine in combination with rituximab for elderly patients with previously untreated B-cell chronic lymphocytic leukemia: A retrospective analysis of real-life practice in Italian hematology departments. Leuk Res . 2015;39(10):1066-1070.

5. Gozzetti A, Candi V, Brambilla CZ, et al. Bruton Kinase Inhibitors in Chronic Lymphocytic Leukemia. Anticancer Agents Med Chem. 2017;17(8):1040-1045.

6. Mauro FR, Galieni P, Tedeschi A, et al. Factors predicting survival in chronic lymphocytic leukemia patients developing Richter syndrome transformation into Hodgkin lymphoma. Am J Hematol . 2017;92(6):529-535.

7. Ducassou S, Ferlay C, Bergeron C, et al. Clinical presentation, evolution, and prognosis of precursor B-cell lymphoblastic lymphoma in trials LMT96, EORTC 58881, and EORTC 58951. Br J Haematol . 2011;152:441-451

8. Olszewski AJ, Gutman R, Eaton CB. Increased fracture risk in patients with untreated chronic lymphocytic leukemia (CLL): a population-based analysis. Blood . 2015;126:878

9. Olszewski AJ, Gutman R, Eaton CB. Increased risk of axial fractures in patients with untreated chronic lymphocytic leukemia: a population-based analysis. Haematologica . 2016;101:e488-e491

10. Fabbri A, Gozzetti A, Marotta G, et al. An unusual presentation of chronic B-cell lymphocytic Leukaemia. Br J Haematol. 2004 Jan;124(2):129

11. Abboud SL, Gordeuk V, Schacter LP, et al. Well-differentiated lymphocytic lymphoma with peripheral blood involvement, osteolytic bone lesions, and hypercalcemia. A case report and review of the literature. Cancer. 1985 Nov 15;56(10):2508-11.

12. Hatum G, Meshkin C, Alkhunaizi S, et al. The Risk of Misdiagnosing the Primary Site Responsible for Bone Metastases in Patients With Chronic Lymphocytic Leukemia and a Second Primary Carcinoma. World J Oncol . 2015;6(2):332-334

13. Katz H, Sagun S, Griswold D, et al. Solitary lytic bone metastasis: a rare presentation of small lymphocytic leukemia. Case Rep Hematol . 2018 Oct 30;2018:6154709.

14. Htet ZM, Gomez C, Ahsan A, et al. Multiple faces of chronic lymphocytic leukaemia: a patient with renal, cardiac and skeletal complications. Case Rep Nephrol . 2019 Mar 12;2019:5390235.

15. Hua J, Ide S, Ohara S, et al. Hypercalcemia and osteolytic bone lesions as the major symptoms in a chronic lymphocytic leukemia/small lymphocytic lymphoma patient: a rare case. J Clin Exp Hematop . 2018 Dec 13;58(4):171-174

16. Langenberg JCM, Bosman WM, Bremer J, Ritchie ED. Pathological fractures in a patient with chronic lymphatic leucaemia without disease progression. BMJ Case Rep . 2015; Feb 25: 2015:bcr2014208118

17. Littlewood TJ, Lydon APM, Barton CJ. Hypercalcemia and osteolytic lesions associated with chronic lymphatic leukaemia (CLL). J Clin Path 1990;43(10):877

18. Narayan H, Bandyopadhyay D, Schmidt K, et al. Successful treatment of a patient with chronic lymphocytic leukaemia (CLL) presenting with bony metastases with aggressive antibody and chemotherapy. Clin Lab Haematol. 2005; 27:405-408

19. Redmond J, Stites D, Beckstead J, et al. Chronic lymphocytic leukemia with osteolytic bone lesions, hypercalcemia, and monoclonal protein.Am J Clin Path 1983;79:616-620

20. 16 Yau V, Christakis M, Ismiil N, et al. Chronic lymphocytic leukemia resembling metastatic bone disease-unusual manifestation. J Pain Symptom Manage . 2003 Dec;26(6):1074-6.

21. Soni P, Aggarwal N, Rai A et al. Chronic lymphocytic leukemia: a rare cause of pathological fracture of the femur. J Investig Med High Impact Case Rep . 2017 Oct 3;5(4): 2324709617735135

22. Dunphy CH, Oza YV, Skelly ME. Previously undescribed form of B-cell chronic lymphoid leukemia 
with IgA expression/secretion and lytic bone lesions. Am J Hematol . 1997 Aug;55(4):208-11.

23. Wright GW, Wiesenfeld D, Seymour JF. Bilateral fracture of the mandible in chronic lymphocytic leukaemia. Case report. Aust Dent J . 1997;42:20-24

24. Aiwaladhi S, Baddoura FK, Haumesser JC, et al. Hypercalcemia and Osteolytic Bone Lesions in B-Cell Chronic Lymphocytic Leukemia: A Case Report. Clinical Leukemia, Vol. 1, No. 1, 57-60, 2006

25. Alanoglu G, Dagdas S, Aki Z. Hypercalcemia and multiple pathological fractures in chronic lymphocytic leukaemia: a case report. Turk J of Haematol. 2003; vol. 20, no. 3, pp. 167-170

26. Greenfield HM, Hunt R, Lee LK, Jowitt SN. B-cell chronic lymphocytic leukaemia with extensive lytic lesions. Eur J Haematol 2006: 76: 356-357

27. Mian M, Cerù S, Billio A, et al. Osteolytic bone lesions as a rare sign of progression of chronic lymphocytic leukemia without evidence of Richter syndrome. Leukemia \&3 Lymphoma , May 2012; 53(5): 993-995

28. Rossi JF, Bataille R, Chappard D, et al. B cell malignancies presenting with unusual bone involvement and mimicking multiple myeloma. Study of nine cases.Am J Med. 1987 Jul;83(1):10-6

29. McMillan P, Mundy G, Mayer P. Hypercalcemia and osteolytic bone lesions in chronic lymphocytic leukaemia. Br Med J 1980; 281:1107

30. Van de Casteele M, Verhoef GEG, Demuynck H, et al. Hypercalcemia, monoclonal protein, and osteolytic bone lesions in chronic lymphocytic leukemia. Ann Hematol 1994;69:79-80

31. Fain O, Selmi A, Dosquet C, et al. Hypercalcemia in B-cell chronic lymphocytic leukemia. Br J Haematol 1994;87: 856-8.

32. Laugen RH, Carey RM, Wills RW, Hess CE. Hypercalcemia associated with chronic lymphocytic leukemia. Arch Intern Med. 1979; 1339:1307

33. Mundy GR, Raisz LG, Cooper R, et al. Evidence for the secretion of an osteoclast stimulating factor in myeloma. $N$ Engl $J$ Med 290:867, 1974

34. Marini C, Bruno S, Fiz F, et al. Functional Activation of Osteoclast Commitment in Chronic Lymphocytic Leukaemia: a Possible Role for RANK/RANKL Pathway. SCIENTIFIC RePOrTs , 7: 14159.

\section{Figure legends}

Figure 1. CT-scan showing left ilium involvement and bone fracture (a and b), subsequently due to disease progression a left clavicule (c) and multiple cranial bone lesions (d).

Figure 2. Hematoxylin and Eosin stain of bone biopsy showing at $2 \mathrm{x}$ (a) and 20x (b) lymphoid infiltrate characterized by small size cells. Immunohistochemical staining (20x) was positive for CD20 (c), CD5 (d), CD23 (e) and Ki67 (f). 

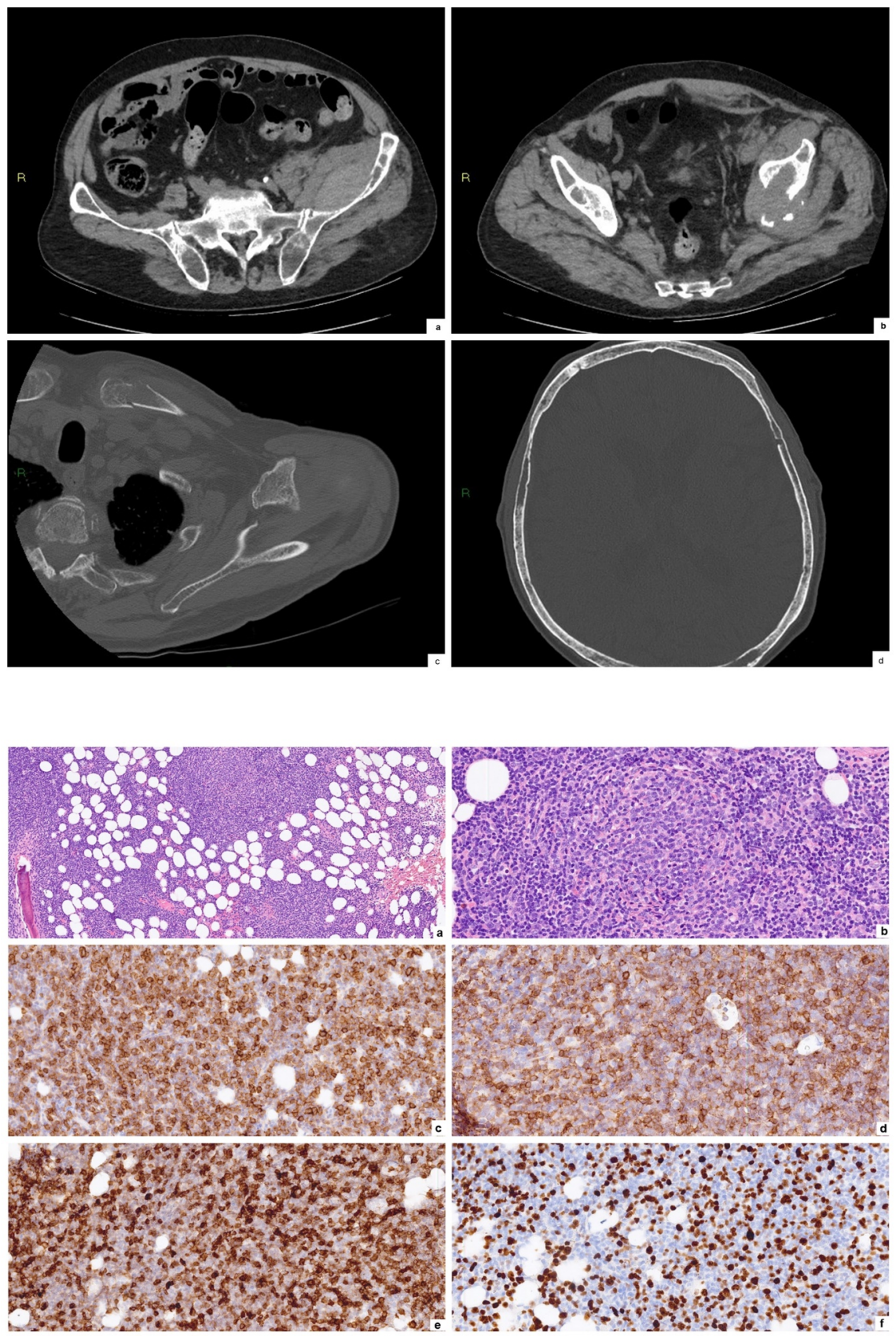

Table 1. Overview of previously reported cases of CLL compromised by osteolytic bone lesions and/or hypercalcemia

\begin{tabular}{|c|c|c|c|c|c|c|c|}
\hline Ref. & $\begin{array}{l}\text { Age/ } \\
\text { Sex }\end{array}$ & $\begin{array}{l}\text { Stage/nev } \\
\text { diagno- } \\
\text { sis }\end{array}$ & $\begin{array}{l}\text { WBC } \quad \text { Hb } \\
\left(\mathbf{1 0}^{9} / \mathrm{L}\right) / \mathrm{Ly}(\mathrm{gg} / \mathrm{dL})\end{array}$ & $\begin{array}{l}\text { Plt } \\
\left(10^{9} / \mathrm{L}\right)\end{array}$ & $\begin{array}{l}\text { M } \\
\text { protein }\end{array}$ & $\begin{array}{l}\text { Bone } \\
\text { lesions }\end{array}$ & Hypercalcefriæatment \\
\hline Laun & $709 / \mathrm{M}$ & IIIC/Y & $352 / 99 \%$ & 76 & $\mathrm{NA}$ & - & CVP \\
\hline
\end{tabular}




\begin{tabular}{|c|c|c|c|c|c|c|c|c|c|}
\hline \multirow{2}{*}{$\frac{\text { Ref. }}{\text { McMillian, }}$} & \multirow{2}{*}{$\begin{array}{l}\text { Age/ } \\
\text { Sex } \\
1980 / \mathrm{F}\end{array}$} & \multirow{2}{*}{$\begin{array}{l}\begin{array}{l}\text { Stage/new } \\
\text { diagno- } \\
\text { sis }\end{array} \\
\mathrm{NA} / \mathrm{y}\end{array}$} & \multicolumn{2}{|c|}{$\begin{array}{l}\text { WBC } \quad \text { Hb } \\
\left(10^{9} / \mathrm{L}\right) / \text { Ly(gg/dL) }\end{array}$} & \multirow{2}{*}{$\begin{array}{l}\text { Plt } \\
\left(10^{9} / \mathbf{L}\right) \\
\text { NA }\end{array}$} & \multirow{2}{*}{$\begin{array}{l}\text { M } \\
\text { protein } \\
\text { NA }\end{array}$} & \multirow{2}{*}{$\begin{array}{l}\begin{array}{l}\text { Bone } \\
\text { lesions }\end{array} \\
+\end{array}$} & \multicolumn{2}{|c|}{ Hypercalcefrimatment } \\
\hline & & & $2.8 / 78 \%$ & 9.3 & & & & + & Chlor \\
\hline \multirow{2}{*}{\multicolumn{2}{|c|}{$\begin{array}{l}\text { Redmon,19865/M } \\
\text { Abboud,19850/M }\end{array}$}} & $\mathrm{NA} / \mathrm{Y}$ & $68.3 / 90 \%$ & 11 & 22 & $\mathrm{~K}(\mathrm{U})$ & + & + & NA \\
\hline & & $\mathrm{NA} / \mathrm{Y}$ & $19.2 / 61 \%$ & 12.9 & $\mathrm{~N}$ & $\mathrm{NA}$ & + & + & $\mathrm{RT}$,Chlor $+\mathrm{F}$ \\
\hline Rossi, 1987 & $74 / \mathrm{M}$ & $\begin{array}{l}\text { Rai } \\
\text { II/Y }\end{array}$ & $80 / 88$ & NA & NA & NA & + & + & NA \\
\hline Rossi,1987 & $72 / \mathrm{F}$ & $\begin{array}{l}\text { Binet } \\
\mathrm{C} / \mathrm{N}\end{array}$ & $95 / 80 \%$ & 12 & 40 & - & - & + & - \\
\hline \multicolumn{2}{|c|}{ Littlewood,199øM } & $\mathrm{NA} / \mathrm{N}$ & $14.8 / 61 \%$ & 9.1 & 14.2 & - & + & + & Chlor+PDN \\
\hline \multicolumn{2}{|c|}{ Littlewood,199 $\emptyset \mathrm{F}$} & $\begin{array}{l}\text { Binet } \\
\mathrm{C} / \mathrm{N}\end{array}$ & $\mathrm{NA} / \mathrm{NA}$ & NA & NA & - & + & + & NA \\
\hline Fain,1994 & $56 / \mathrm{M}$ & $\begin{array}{l}\text { Binet } \\
\mathrm{C} / \mathrm{N}\end{array}$ & $98.1 / 90 \%$ & 9 & 78 & NA & + & + & $\mathrm{CHOP}$ \\
\hline \multicolumn{2}{|c|}{ Wright,199772/F } & $\mathrm{NA} / \mathrm{N}$ & $9.1 / 4.45$ & 12.2 & 624 & - & + & - & surgery \\
\hline \multicolumn{2}{|c|}{ Dunphy,199772/M } & $\begin{array}{l}\text { Binet } \\
\mathrm{C} / \mathrm{Y}\end{array}$ & $26.4 / 86 \%$ & 8.2 & 85 & $\operatorname{IgA~k}$ & + & - & $\begin{array}{l}\text { Chlor }+ \text { PDN } \\
\text { VAD }\end{array}$ \\
\hline \multicolumn{2}{|c|}{ Alanoglu,200731/M } & $\begin{array}{l}\text { Rai } \\
\mathrm{I} / \mathrm{Y}\end{array}$ & 154 & 11 & 283 & - & + & + & CVP \\
\hline Yau,2003 & $66 / \mathrm{F}$ & $\mathrm{I} / \mathrm{Y}$ & $16.2 / 0.6$ & 14.9 & 177 & NA & + & - & $\begin{array}{l}\text { RT, } \\
\text { CVP }\end{array}$ \\
\hline \multicolumn{2}{|c|}{ Fabbri,2004 63/M } & $\begin{array}{l}\text { Binet } \\
\mathrm{C} / \mathrm{Y}\end{array}$ & $43.5 / 78 \%$ & 10.8 & 196 & NA & + & NA & $\mathrm{RT}, \mathrm{FC}$ \\
\hline \multicolumn{2}{|c|}{ Narayan,20083/M } & $\mathrm{NA} / \mathrm{N}$ & $\mathrm{NA} / 40 \mathrm{X} 10^{9}$ & $9 / 110.1$ & 21.3 & NA & + & + & CHOP \\
\hline \multicolumn{2}{|c|}{ Ailawadhi,20656/M } & $\begin{array}{l}\text { Binet } \\
\mathrm{C} / \mathrm{N}\end{array}$ & $117 / 98 \%$ & 8.1 & 139 & $\operatorname{IgM~k}$ & + & + & - \\
\hline \multicolumn{2}{|c|}{ Greenfield,2\$16/M } & $\begin{array}{l}\text { Binet } \\
\text { A/N }\end{array}$ & $\mathrm{NA} / \mathrm{NA}$ & NA & NA & $\operatorname{IgG~k}$ & + & - & NA \\
\hline Mian,2011 & $60 / \mathrm{M}$ & $\mathrm{NA} / \mathrm{N}$ & $3.52 / 57 \%$ & 12.7 & 6.2 & - & + & - & $\mathrm{CHOP}$ \\
\hline Hatoum,201 & $151 / \mathrm{M}$ & $\mathrm{NA} / \mathrm{N}$ & NA & NA & NA & NA & + & - & $\mathrm{RT}$ \\
\hline Langenberg & 3975 & $\mathrm{NA} / \mathrm{N}$ & $\mathrm{NA} / \mathrm{NA}$ & NA & NA & NA & + & NA & FCR \\
\hline Koutroump & ato,, 20116 & $\begin{array}{l}\text { Rai } \\
\text { III/Y }\end{array}$ & $10.9 / 93.6 \%$ & 9.1 & 18.9 & - & - & + & $\mathrm{BR}$ \\
\hline Soni, 2017 & $85 / \mathrm{F}$ & $\begin{array}{l}\text { Binet } \\
\mathrm{C} / \mathrm{Y}\end{array}$ & $107 / \mathrm{NA}$ & 10.2 & 149 & NA & + & - & - \\
\hline Hua, 2018 & $40 / \mathrm{F}$ & $\begin{array}{l}\text { Rai } \\
\text { III/Y }\end{array}$ & $6.5 / 65 \%$ & 7 & 12.4 & $\mathrm{k}$ & + & + & $\mathrm{FCR} / \mathrm{BR}$ \\
\hline Htet, 2018 & $55 / \mathrm{F}$ & $\mathrm{IA} / \mathrm{N}$ & $\mathrm{L}=56.5$ & NA & NA & $\operatorname{IgG} \lambda$ & + & - & $\mathrm{BR}$ \\
\hline Katz,2018 & $76 / \mathrm{F}$ & $0 \mathrm{~A} / \mathrm{Y}$ & $4.4 / 0,66$ & 13.7 & 178 & NA & + & $\mathrm{NA}$ & - \\
\hline $\begin{array}{l}\text { Present } \\
\text { case }\end{array}$ & $74 / \mathrm{M}$ & IVC & $2.3 / 15 \%$ & 11.4 & 137 & $\mathrm{NO}$ & + & + & Venetoclax \\
\hline
\end{tabular}

Adapted from Hua et al. ${ }^{15}$ 
Abbreviations: WBC, white blood cell; Lym, lymphocyte; Hb, hemoglobin; Plt, platelet; CHOP, cyclophosphamide, doxorubicin, vincristine, prednisone; CVP, cylophosphamide, vincristine, prednisone, Chlor, chlorambucil; FCR, fludarabine, cyclophosphamide, rituximab; ; FC, fludarabine, cyclophosphamide; FR, fludarabine, rituximab; BR, bendamustine, rituximab; PDN, prednisolone; CR, complete remission; NA; not available, N normal; PDN prednisone; RT, radiotherapy; VAD (Vincristine, Adriamycin, Dexametasone). 